\title{
Organisational climate from view point of motivation in district hospital, India
}

\author{
Bhaskar Purohit $^{1^{*}}$, Ashok Wadhwa ${ }^{2}$ \\ ${ }^{1}$ Indian Institute of Public Health, Gandhinagar, India; * Corresponding Author: purohit.bhaskar@gmail.com \\ ${ }^{2}$ Community Health Center, Raipur, India
}

Received 10 April 2012; revised 1 May 2012; accepted 18 May 2012

\begin{abstract}
Organisational Climate (OC) has been an important topic of research in Organisational Development. There are several frameworks and approaches to study OC. One such framework focuses on the effect of OC on motivation. Although studying $\mathrm{OC}$ from viewpoint of motivetion is an important one, there is very limited research in Indian public health system on assessing $O C$ from the view point of motivation. The present study uses a comprehensive framework that focuses on assessing $O C$ from the view point of motivation in a government district hospital. The overall objective of the study was to assess the OC of a District Hospital (DH) from the view point of motivation. A total of 66 staff (all from the same district hospital) participated

ees always look for approval from their seniors; assistance of others in developing oneself; a need to check with others who are more knowledgeable. Similarly high score for control motive indicates that order is maintained in organisation; indicates display of personal power; a desire to stay informed and an urge to monitor events and to take corrective action when needed. When the two motives are combined, the study indicates a dependency-control climate profile which means that the organisational practices are similar to government offices, where subordinates have no say in decision making and they have to follow the established rules of the organisation. Such organisations have clearly laid communication channels controlled from higher authority indicating typical characteristics of a beaurocratic organisation.
\end{abstract} in the study that included 12 Class I doctor specialists; 14 Class II doctors and 40 Class III staff The data was collected using a validated instrument called Motivational Analysis of Climate (MAO-C). The instrument included six needs or motives and twelve dimensions of organisational climate that were ranked by individuals according to their perception. Based on the ranks, final scores were calculated that reflected the dominant climate (highest score for a particular motive) and backup climates (second highest score for a particular motive). Also a combination of the two motives, dominant and back up motives or climates indicated a particular OC. According to the study, the dominant climate in the organisation was that for Dependency motive while the backup climate for the organisation was for Control motive. According to the literature, both Dependency and Control motives are dysfunctional climates. A high dependency motive indicates that the overall organisational climate is characterized by no initiatives by the people and the employ-
Keywords: Organizational Climate; Motivation; Needs; Motives; Bureaucracy; India

\section{INTRODUCTION}

Organisational Climate (OC) has been an important topic of research in West. It also gained importance in India, however only in the corporate sector. OC significantly influences the behaviour of organisational members [1]. There are many suggested definitions and frameworks to study OC. Some of the popular definitions of OC are as follows: Forehand and Gilmer [1] defined OC as "set of characteristics that describe the organisation and distinguish it from other organisations and such characteristics influence the behavior of people in the organisation”. According to Pareek [2] climate can be defined as "Perceived attributes of an organisation and its sub systems, as reflected in the way organisations deals with its members, groups and issues". Yet another definition of OC is as follows: "Climate is held to be a summary perception of how an organisation deals with its members and environments, and thus develops speci- 
fically from internal factors primarily under managerial influence" [3].

While there is enough research and evidence about influence of organisational climate on job satisfaction [4], the evidence that demonstrates a link between organisational climate and patient outcomes in health sector is very limited. According to a research study done with more than 500 National Health Service (NHS) teams found that innovative and participative climates were linked to effectiveness in delivering patient care [5]. Similarly a study found positive and significant relationship between team climate and positive patient evaluations [8]. A study of teaching hospital in Ghana indicates that OC factors like stress and organisational pride are important factors for employees' intentions to quit [7].

Litwin and Stringer [8] were the first to demonstrate that employees with a given motive/needs (motives that were earlier suggested by McClelland [9]) are most effective when OC is conducive for that motive. OC has important outcomes at individual, group and organisational levels [10] and can greatly influence job satisfaction [4], individual job performance [11], and organisational performance[12,13]. OC also helps in determining organisational success [14], and is important for achieving organisational effectiveness [15].

Framework and Approach for Measuring in OC: There are several frameworks for the measuring OC $[1,10,16]$. One conceptual framework of climate proposed by Litwin and Stringer [8] focuses on motivational linkages. This framework suggests effect of OC on the motivation of its members based on the motives/needs suggested by Mc Cleland-need for power, need for achievement and need for affiliation. Based on some of the important frameworks and definitions proposed earlier, a more comprehensive framework and instrument on assessing OC from the viewpoint of motivation was developed by Pareek $[2,16,17]$. This framework was selected for this study for two reasons. One, this is a very comprehensive framework that looks at OC and motivational linkages and is based on needs or motives that were earlier studies by Mc Cleland (the framework is expanded to 3 more needs/motives in addition to Mc Cleland's three needs). Secondly, the evidence about factors influencing OC in health sector is limited to issues like leadership and communication [18]. Since there is hardly any research in Health sector in India that focuses on motivational linkages of OC, Pareek's framework and instrument of assessing OC from viewpoint of motivation was selected. According to this framework, the climate can be characterized as having one of the following dominant motives.

Achievement Climate: This motive is characterized for concern for excellence, competition in terms of standards set by others or by oneself, the setting of challenging goals for oneself, awareness of the obstacles that might be encountered in attempting to achieve these goals and persistence in trying alternative paths to one's goals [2]. An achievement climate seems to contribute to effectiveness, satisfaction, and a sense of internality. Achievement climate has significant positive correlation with job involvement. Positive correlations also exist between Organizational commitment, organizational attachment, job satisfaction and effectiveness with achievement motive [19]. While negative correlation between role stress and climates of achievement $[19,20]$.

Affiliation Climate: Affiliation is concern for establishing and maintaining close, personal relationships; and emphasis on friendship and tendency to express one's emotions [2]. An affiliation climate tends to lower both Job satisfactions and effectiveness [19] and increase role erosion and feelings of personal inadequacy. Positive correlation between role stress climate of affiliation [19, 20].

Expert Influence Climate: This motive is characterized by concern for making an impact on others, a desire to make people do what one thinks is right, and an urge to change situation and to develop people [2]. A climate characterized by expert influence seems to contribute to organisational attachment; Negative correlation between role stress and climates of Expert Influence [19,20].

Control Climate: This motive is concerned for orderliness; a desire to be stay informed; an urge to monitor events and to take corrective action when needed and to display personal power [2]. A control climate seems to lower role efficacy, job satisfaction, organisational commitment, organisational attachment and total effectiveness and to foster relatively high levels of role stress. Positive correlation between role stress climate of affiliation $[19,20]$.

Extension Climate: This motive is characterized by concern for others; interest in subordinate goals; urge to be relevant and useful to large groups including society [2]. A climate characterised by extension seems to contribute to organisational commitment [19] Negative correlation between role stress and climates of Extension $[19,20]$.

Dependency Climate: This is concerned with desire to help others in developing oneself; association with people having higher knowledge and higher status; tendency for subordination, and approval from higher-ups [2]. Positive correlation between role stress climate of dependency $[19,20]$.

\section{METHODS}

Study Design and Respondents: As hardly any studies have been done to assess OC from the view point of motivation in the public healthcare delivery system in 
India, we call it an exploratory study as it aimed as assessing employees' perception about District Hospital's $(\mathrm{DH})^{1}$ climate from the view point of motivation. Since the time and resources available for the study were very limited, only one district from the state was randomly selected. As per the Health Delivery system in India, there is only 1 govt. DH per district, hence the data was collected from only $1 \mathrm{DH}$ that was part of the selected district. The DH under study caters to urban and rural population in one of the districts in India. It provides referral services to Community Health Centre (CHC) ${ }^{2}$ and Primary Health Centres (PHC) ${ }^{3}$ in the district. Respondents included Class I, II and III ${ }^{4}$ staff, all working in the same district hospital. Only class-IV employees were excluded from the study as they include drivers, cleaners etc who would have found it difficult to understand the study questionnaire. A total of 66 staff from the selected district hospital participated in the study that included 12 Class I Specialists; 14 Class II M.Os and 40 Class III Employees (including Matron, nursing sisters, Staff nurses, technicians in different fields, pharmacists).

Data Collection Tool: For the purpose of the study, a validated instrument called Motivational Analysis of Climate (MAO-C) was used. This instrument has been developed by Late Prof. Udai Pareek [2]. The instrument included six needs or motives and twelve dimensions of organisational climate that were ranked by individuals according to their perception to find out the climate. The choice of MAO-C was made for the following reasons. Firstly, MAO-C has been assessed as a good inventory for the measuring OC [21]. Secondly, MAO-C has been used in Indian corporate sector and has been found to be relevant for studying OC in companies [22-24]. Thirdly, the instrument has established retest reliability [20] and established construct validity. MAO-C is based on 12 dimensions of organisational working which are orientation, interpersonal relationships, supervision, problem management, management of mistakes, conflict management, communication, decision making, trust, management of rewards, risk taking, and innovation and change. Thus the instrument included twelve dimensions of Or-

\footnotetext{
${ }^{1}$ District Hospital is Public Hospital that caters to the health needs of the entire district providing mainly tertiary care.

${ }^{2} \mathrm{CHC}$ is a 30 bedded hospital that constitutes the secondary level of health care and provide referral as well as specialist health care to the rural population at the block level. It caters to 80,000 - 120,000 population.

${ }^{3} \mathrm{PHC}$ covers a population of 20,000 in hilly, tribal, or difficult areas and 30,000 populations in plain areas with $4-6$ indoor/observation beds. It acts as a referral unit for 6 sub-centres and refer out cases to CHC (30 bedded hospital) and higher order public hospitals located at sub-district and district level.

${ }^{4}$ Class I includes medical doctors with a post graduate degree or who hold higher level administrative positions in the health system; Class II includes Medical doctors without a specialization; Class III includes other Para medical staff like Nurses, Auxiliary Nurse Midwife, Lab Technician, Pharmacist etc.
}

ganisational Climate and six motives. Each of the dimensions had 6 statements (each statement representing a particular motive) that a respondent had to choose. In this way, there were 12 categories that represented 12 dimensions of organisational climate. The respondents were asked to rank the statements in each category from 6 to 1 where 6 indicated most like the situation in their organisation and ranking 1 indicated least like the situation in their organisation.

The individual ratings were aggregated and converted into Index scores on 100 point scale. These scores reflected the dominant climate (highest score) and backup climates (second highest). Also a combination of the two motives, Dominant and back up motives (Climates) indicated a particular organisation climate. Therefore, there can be as many as 30 combinations are possible. In general, achievement, expert influence and extension climates have been found to be functional and motives of control, dependency and affiliation have found to be dysfunctional. The level of functionality also depends on the index score. While there are no norms available for Public Health organisations, an index score 50 to 65 is considered to normal score; 65 to 75 is good and above 75 is very good score [13].

Data Analysis: The columns in the scoring sheet represented the scores for the six motives while the rows represented the scores for each of the 12 dimension of the climate. For analysis, the numbers in each vertical column (for all the respondents) in the scoring sheet (representing the six motives) were added to get a total of each of the six motives. Further, average scores were calculated for each motive that theoretically could range from 12 to 72 . These average scores were further converted to a 100 point scale called index scores. This was done to make the interpretation of the scores more meaningful and to show the relative strength of the climate with regard to other motives. For this, a conversion table was used to convert the mean scores for each motive to an Index score that ranged from 0 to 100 . Mean index score was ascertained for each motive; the first highest score called the dominant motive and the second highest score called the backup motive. If the index number for a particular motive was greater than 50 , the climate was considered relatively stronger. If the index number is less than 50 , the climate is relatively weak for that motive. Following formula was used to arrive at the index for each motive:

$$
\text { MAO }- \text { C Index }=(S-12) \times 100 / 60
$$

Climate Profiles: Analysis and combination of an organisation's highest or dominant score and its second highest or back-up score can give basic characterization of that organisation's climate. When the six motives are combined in pattern of dominant or highest and secon- 
dary or back-up styles, thirty organisational profiles are possible [2]. In general the achievement, expert influence, and extension are functional, and control, dependency and affiliation are dysfunctional for an organisation [2]. Based on research, it can be said that generally business firms have high achievement climate; Technical firms are high on expert power; government units are high on control motive; traditional organisations are high on dependency; service organisations are high on extension and organisations such as clubs are high on affiliation [2].

The overall objective of study was to assess the OC from the view point of motivation in one $\mathrm{DH}$ in India. The specific objectives of the research study were to study which motives drive the $\mathrm{DH}$ organisation and to assess the overall climate profile of the DH based on dominant and back up motives.

\section{RESULTS AND DISCUSSION}

Overall Climate of Organisation: On the basis of the Tables 1 and 2, it can be said that the dominant climate in the organisation was that for dependency motive with an index score of 78. Similarly, the backup climate for the organisation was for Control Motive with an index score of 75. According to the literature, both Dependency and Control motives are dysfunctional climates. As discussed earlier, since no norms are available for government hospitals, scores exceeding 70 to 75 in general are considered to be very high.

Table 1. Profile of respondents based on their nature of appointment, duration of service and position held.

\begin{tabular}{|c|c|c|}
\hline \multicolumn{3}{|c|}{ Profile of Respondents } \\
\hline Type of Appointment & Number & Percent \\
\hline Regular & 61 & 92 \\
\hline Contractual & 5 & 8 \\
\hline Total & 66 & 100 \\
\hline Duration of Service in Years & Number & Percent \\
\hline $0-9$ & 9 & 14 \\
\hline $10-19$ & 7 & 11 \\
\hline $20-29$ & 38 & 57 \\
\hline 30 or more & 12 & 18 \\
\hline Total & 66 & 100 \\
\hline Position Held & Number & Percent \\
\hline Class 1 & 12 & 18 \\
\hline Class 2 & 14 & 21 \\
\hline Class 3 & 40 & 61 \\
\hline Total & 66 & 100 \\
\hline
\end{tabular}

Table 2. Mean Score and index score for six motives.

\begin{tabular}{lccc}
\hline Motives & $\begin{array}{c}\text { Mean } \\
\text { Score }\end{array}$ & $\begin{array}{c}\text { Mean Index } \\
\text { Score }^{*}\end{array}$ & $\begin{array}{c}\text { Standard } \\
\text { Deviation }\end{array}$ \\
\hline Achievement & 53 & 68 & 9 \\
Expert Influence & 33 & 35 & 8 \\
Extension & 34 & 37 & 4 \\
Control & 57 & 75 & 6 \\
Dependency & 59 & 78 & 4 \\
Affiliation & 20 & 13 & 7 \\
\hline
\end{tabular}

*After using the conversion formula to convert the mean scores to 100 point scale.

The Dependency Climate: An index score of 78 for dependency motive indicates a very high score for the motive. In general it can be said that the organisational climate is characterized by no initiatives by the people; Class III and II employees always look for approval from their seniors or higher ups. Prevalence of ddependency climate in public sector has been reported by Trivedi [25].

The Control Climate: An index score of 75 for control motive indicates a high score for the motive. This motive is dysfunctional and indicates that order is maintained in the $\mathrm{DH}$; such a score displays personal power; characterization of a beaurocratic organisation. The dominance of Control climate in the public sector has been reported by Sandra and Frans [26].

Overall Profile of the Organisation Based on Dominant and Back Up Climate: When we combine the dominant and back up motive, the study indicates a dependency-control climate profile. The climate profile of dependency-control indicates that the practices of the $\mathrm{DH}$ are similar to government offices, where subordinates have no say in decision making and they have to follow the established rules of the organisation. Such organisations generally have clearly laid communication channels controlled from higher authority (beaurocratic nature) by few people. The decision making also lies with the higher authority with very little or no involvement of subordinates. Dependency-Control climate [2] indicates that the decision making of the $\mathrm{DH}$ is controlled by a few officers/individuals from the health system (generally Class I and administrative services officers working at the Directorate and Commissionerate level). The findings also indicate that the $\mathrm{DH}$ has clearcut channels of communication and the senior officers (outside the DH but who are very much part of the health system) give the final approval for all decisions.

Other Climates of the Organisation: The findings also suggest that third highest mean index score was 68 
for achievement climate. Although this is a functional climate, the overall score for the climate is not as high as scores for dependency and control. This means that there is moderate climate for concern for excellence among the employees and less competition among the people to strive for standards set by the health system or by oneself. It also suggests that goals set for $\mathrm{DH}$ or for oneself are not very challenging $[2,13]$.

The index score for Expert Influence is 35 which is a relatively low score. It indicates that concern of the people and organisation for making an impact on others is not high. The low score also indicates that the organization (including the DH and Health system as a whole) does not give enough importance to develop its people.

The index score for Extension climate was 37 which is a low score. Therefore it can be said that seniors' interest in subordinate goals is very less; and the respondents perception about its organization to be relevant and useful to large groups including society is very less.

The Table 3 indicates that profile of Respondents have some impact on the different motives. The dominant motive for Class I is Control; for Class II is Control and Dependency and for Class III it is again Dependency. So what can be inferred from the data is that according to Class III respondents, organisational climate is characterized by no initiatives by the people and they always look for approval from their seniors or higher ups. This may be due to hierarchical nature of the profile. While high score for Control in Class I and II indicates that order is maintained in organisation and they enjoy display of personal power.

\section{CONCLUSIONS}

The study assessed OC from the view point of motivation in a DH in India. The study found that the OC in the DH is perceived to be dominated by the need to Dependency followed by need to Control. According to literature, both the needs/climates are dysfunctional and

Table 3. Mean scores of motives based on Profile of respondents.

\begin{tabular}{lccc}
\hline Motives & $\begin{array}{c}{ }^{*} \text { Mean score of } \\
\text { Class I n = 12 }\end{array}$ & $\begin{array}{c}\text { Mean score of } \\
\text { Class II n = 14 }\end{array}$ & $\begin{array}{c}{ }^{*} \text { Mean score of } \\
\text { Class III n = 40 }\end{array}$ \\
\hline Achievement & 58 & 54 & 46 \\
Expert Influence & 30 & 31 & 40 \\
Extension & 29 & 30 & 43 \\
Control & 64 & 58 & 50 \\
Dependency & 59 & 58 & 60 \\
Affiliation & 20 & 20 & 19 \\
\hline
\end{tabular}

* These are mean scores without using the conversion formula to convert the mean scores into index scores. significantly correlated with role stress. The scores indicate that there is beaurocratic control by high authorities and communication is top-down and one way. Also, subordinates submit to supervisors and do not take any initiatives and for small decision as they depend on approval from their seniors.

Also, as already discussed, the study findings indicate that a combination of control-dependency is characterized by a typical beaurocratic organisation. This means that the power remains in the hands of high in hierarchy. However, to be more effective it needs to be changed. Such changes may include having more decentralized processes in decision making at institution level. Similarly, the communication channels are perhaps not very clear in the organisation and are often controlled from higher authority (beaurocratic nature) by few people and they make all the decisions without involvement of subordinates. Hence it is recommended that subordinates should be given more responsibility and autonomy that will allow them to take decisions within their own sphere of work thereby increasing accountability.

Following small steps could be taken to address the climate that is currently dominated by need to control and dependency.

1) The supervision should not focus on only fault finding for subordinates. Rather it should be taken as learning process by the subordinates and seniors.

2) Subordinates must be encouraged to find solutions to problems and expert should be consulted only when needed. However, whenever required, seniors must be available to guide their subordinates.

3) Communication should be two way and subordinates must be involved in decision making processes.

4) The climate can be improved by giving more responsibility to the employees by setting more challenging goals. Such goals should have a clear link to reaching the people out of institution for greater benefit of the organisation and the society.

More research and focus should be channeled to study the importance of OC and its motivational linkages. Such work could be useful in understanding the internal motivational needs of the healthcare workers to design more effective management systems and practices.

\section{STRENGTHS AND LIMITATIONS}

One of the limitations of the study is that it uses and relies on the perception of employees to assess OC of the $\mathrm{DH}$. According to the literature, assessing employee perception about OC can be an effective way of measuring OC. However, there could be more approaches of measuring the OC which the current study did not use. Secondly, due to time and resource scarcity, only one district was selected and hence the sample size was relatively 
small. However authors want to emphasize here that despite the small sample size, such studies have hardly been done in India in the Public Healthcare Delivery system and can provide further impetus to research in this area. Furthermore, research findings of the study that the $\mathrm{DH}$ functions like a typical beaurocratic organization are corroborated with research done with government organizations in other sectors. Hence we feel that a sample of 66 was a decent number and findings based on this sample size may be generalized to similar health facilities that are managed by the state government. Thirdly, as it was an exploratory study that only aimed at assessing OC prevailing in the $\mathrm{DH}$, hence developing a causal link or correlation between profile of respondents and its impact on type of OC may not possible. This is because the reasons for why individuals ranked particular statement were not explored. Lastly, the data does not represent other health facilities like CHCs and PHCs; and other districts, blocks or states. Hence, it will be important to have representation of various health centers like DH, CHC's and PHC's as well as various districts and states to be able to make cross comparisons among different groups. More research and focus should be channeled to study the importance of OC and its motivational linkages.

\section{ETHICAL CONSIDERATIONS}

To maintain confidentiality of the respondents, name of the study district and hospital have not been disclosed in the manuscript.

\section{ACKNOWLEDGEMENTS}

The authors are grateful to Late Prof. Udai Pareek for allowing the authors to use his framework, definitions and instrument for the study. His permission for the use of the same was taken. The authors would also like to thank all the participants of the study.

\section{REFERENCES}

[1] Forehand, G.A., and Von Haller, G. (1964) Environmental variations in studies of organisational behaviour. Psychological Bulletin, 62, 361-382. doi:10.1037/h0045960

[2] Pareek, U. (2002) Training instruments in HRD and OD. 2nd Edition, Tata McGraw-Hill, Boston.

[3] Ostroff, C. and Schmitt, N. (1993) Configurations of organisational effectiveness and efficiency. Academy of Management Journal, 36, 1345-1357. doi:10.2307/256814

[4] Mathieu, J.E., Hoffman, D.A. and Farr, J.L. (1993) Job perception-Job satisfaction relations: An empirical comparison of three competing theories. Organisational Behaviour and Human Decision Processes, 56, 370-387.

[5] Borrill, C., West, M.A., Shapiro, D. and Rees, A. (2000) Team working and effectiveness in health care. British Journal of Health Care, 6, 364-371.
[6] Bower, P., Campbell, S., Bojke, C. and Sibbald, B. (2003) Team structure, team climate and the quality of care in primary care: An observational study. Quality and Safety in Healthcare, 12, 273-279. doi:10.1136/qhc.12.4.273

[7] Adjei, A. (2008) Organisational climate and turnover in health sector: The case of the Korle-Bu Teaching Hospital in Ghana. http://hdl.handle.net/10012/3987

[8] Litwin, G.H. and Stringer, R.A. Jr. (1968) Motivation and organisational climate. Division of Research, Harvard Business School, Boston.

[9] McClelland, D. (1961) Theory of needs. http://www.12manage.com/methods_mcclelland_theory_ of_needs.html

[10] Patterson, M.G., West, M.A., Shackleton, V.J., Dawson, J. F., Lawthom, R., Maitlis, S., Robinson, D.L. and Wallace, A.M. (2005) Validating the organisational climate measure: Links to managerial practices, productivity and innovation. Journal of Organisational Behaviour, 26, 379408. doi:10.1002/job.312

[11] Brown, S. and Leigh, T.W. (1996) A new look at psychological climate and its relationship to job involvement, effort, and performance. Journal of Applied Psychology, 81, 358-368. doi:10.1037/0021-9010.81.4.358

[12] Patterson, M.G., Warr, P.B. and West, M.A. (2004) Organisational climate and company performance: The role of employee affect and employee level. Journal of Occupational and Organisational Psychology, 77, 193-216.

[13] Pareek, U. (2005) Training instruments in HRD and OD. 2nd Edition. Tata McGraw-Hill, Boston.

[14] Burton, R.M., Lauridsen, J. and Obel, B. (2004) The impact of organisational climate and strategic fit on firm performance. Human Resource Management, 43, 67-82. doi:10.1002/hrm.20003

[15] Gunbayi, I. (2007) School climate and teachers' perceptions on climate factors: Research into nine urban high schools. The Turkish Online Journal of Educational Technology, 6, Article 7.

[16] Pareek, U. (1989). Motivational analysis of organisationsclimate (MAO-C), In: Pfeiffer, J.W., Ed., The 1989 annual. University Associates, San Diego, 161-171.

[17] Pareek, U. (2004) Understanding organisational behaviour. Oxford University Press, New Delhi.

[18] Burningham, C. and West, M.A. (1995) Individual, climate and group interaction processes as predictors of work team innovation. Small Group Research, 26, 106-118. doi:10.1177/1046496495261006

[19] Khanna, B. (1985) Relationship between Organisational climate and organisational role stress and their impact upon organisational effectiveness: A case study. Ph.D. Thesis, Banaras Hindu University, Varanasi.

[20] Sen, P.C. (1982) A study of personal and organisational correlates of role stress and coping strategies in some public sector banks. Doctoral Dissertation, Gujarat University, Ahmedabad.

[21] Gordon, J. (2004) Pfeiffer classic inventories, questionnaires, and surveys for training and development. John Wiley \& Sons, San Francisco. 
[22] Srivastav, A.K. (2006). Organisational climate as a dependent variable-Relationship with role stress, coping strategy and personal variables. Journal of Management Research, 6, 125-136.

[23] Srivastav, A.K. (2007) Achievement climate in public sector-A cross functional study on relationship with stress and coping. IIMB Management Review, 19, 415-425.

[24] Kunnanatt, J.T. (2007) Impact of ISO 9000 on organisational climate. International Journal of Manpower, 28, 175-192. doi:10.1108/01437720710747983
[25] Trivedi, P. (2005) Designing and implementing mechanisms to enhance accountability for state owned enterprises. Public Enterprise and Its Management: New Opportunities and Unresolved Challenges (UN Expert Group Meeting on Re-Inventing Public Enterprise and Its Management), 27-28 October 2005, New York.

[26] Sandra, V.T. and Frans, L.L. (2002) The performance paradox in the public sector. Public Performance \& Management Review, 25, 267-281. doi:10.2307/3381236 